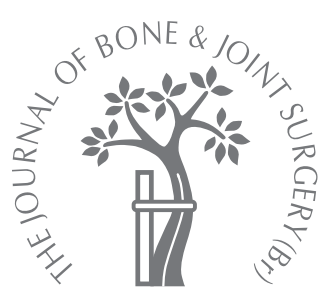

M. Diab,

J. M. Poston,

P. Huber,

A. F. Tencer

From the University

of California, San

Francisco, San

Francisco, USA
M. Diab, MD, Associate Professor, Chief of Paediatric Orthopaedics

Department of Orthopaedic Surgery

University of California, MU320W, 500 Parnassus Avenue, San Francisco, California 94143-0728, USA.

J. M. Poston, BS, Medical Student

P. Huber, BS, Research

Assistant

A. F. Tencer, PhD, Professor Department of Orthopaedics and Sports Medicine

University of Washington

Harborview Medical Centre

MS-359798, 325 Ninth

Avenue, Seattle, Washington 98104, USA.

Correspondence should be sent to Dr M. Diab; e-mail: diab@orthosurg.ucsf.edu

(C)2005 British Editorial

Society of Bone and

Joint Surgery

doi:10.1302/0301-620X.87B6.

$15543 \$ 2.00$

$J$ Bone Joint Surg [Br] 2005;87-B:879-83.

Received 7 April 2004;

Accepted after revision

4 October 2004

\title{
The biomechanical effect of radial shortening on the radiocapitellar articulation
}

\begin{abstract}
Repeated trauma to the radial head may be one of the causative factors in the genesis of osteochondritis dissecans of the capitellum. We measured the force, contact area and pressure across the radiocapitellar articulation of the elbow before and after radial shortening osteotomy in five fresh-frozen cadaver upper limbs with loads of 45,90 and $135 \mathrm{~N}$, respectively. Measurements were made on pressure-sensitive film placed in the radiocapitellar articulation with the forearm in the supinated, neutral and pronated positions before and after radial shortening. Radial shortening significantly reduced the mean force and contact area across the radiocapitellar articulation in all positions of the forearm.
\end{abstract}

Osteochondritis dissecans of the capitellum is a rare but well-recognised condition. Aetiological factors for this include primary disturbance of growth, ${ }^{1}$ genetic predisposition and repetitive trauma, as evidenced by its frequent occurrence in gymnasts ${ }^{2}$ and baseball players. ${ }^{3}$ It is often associated with pain in the elbow, stiffness, loose bodies, disturbance of growth and premature osteoarthritis. ${ }^{3-7}$

Non-surgical treatment consists of modification of activity and the use of non-steroidal anti-inflammatory agents, with or without short-term immobilisation. ${ }^{8}$ Arthroscopic drilling, debridement of the lesion and removal of loose bodies ${ }^{3,9-12}$ are the mainstays of surgical treatment. The long-term outcome has ranged from satisfactory ${ }^{13}$ to fair, with half of patients experiencing chronic pain. ${ }^{14}$ Residual symptoms have been associated with extensive lesions, osteoarthritis of the elbow and large osteochondral defects especially when triangular avulsion fragments were present. ${ }^{15}$ Other surgical treatments have included closingwedge osteotomy of the capitellum, ${ }^{6}$ bone-peg grafting, ${ }^{16}$ osteochondral allografting ${ }^{17}$ and excision of the radial head. ${ }^{4}$

Treatment of osteochondritis dissecans of the capitellum remains controversial because all forms of treatment have been associated with a poor outcome. ${ }^{1,8}$ Radial shortening is a procedure which may reduce the force across the radiocapitellar joint, alleviate the symptoms and improve the functional outcome of the osteochondritis. As a first step in studying this procedure we investigated the biomechan- ical effect of radial shortening on the loading characteristics across the radiocapitellar joint as a potential treatment for osteochondritis dissecans of the capitellum.

\section{Patients and Methods}

Preparation of specimens. Six fresh-frozen cadaver upper limbs were harvested at the level of the mid-shaft of the humerus. Primary abnormalities of the bones and joints, including osteoarthritis, previous operation or deformity were ruled out radiologically and by examination. The soft tissues were dissected only from the proximal $5 \mathrm{~cm}$ of the humerus, which was potted in plastic tubing of $2.5 \mathrm{~cm}$ in diameter using dental cement.

The radiocapitellar articulation was exposed through a lateral approach to the elbow $5 \mathrm{~cm}$ wide. A capsulotomy was performed anterior to the collateral ligaments so that pressure-sensitive film (Fuji Pressorsensor; C. Itoh and Co, New York) could be inserted between the radial head and the capitellum. Three holes were drilled transversely into the proximal end of the radius, about $5 \mathrm{~mm}$ distal to its articular surface, to accommodate a Steinmann pin which was inserted into one hole so that it did not interfere with the function of the radius. The protruding end of the pin was bent at a right angle. When the pressure film was inserted, its protruding tail was pressed against the end of the pin to create a reference mark on the film. This allowed prints to be superimposed on each other and showed the position of the areas of contact recorded on 


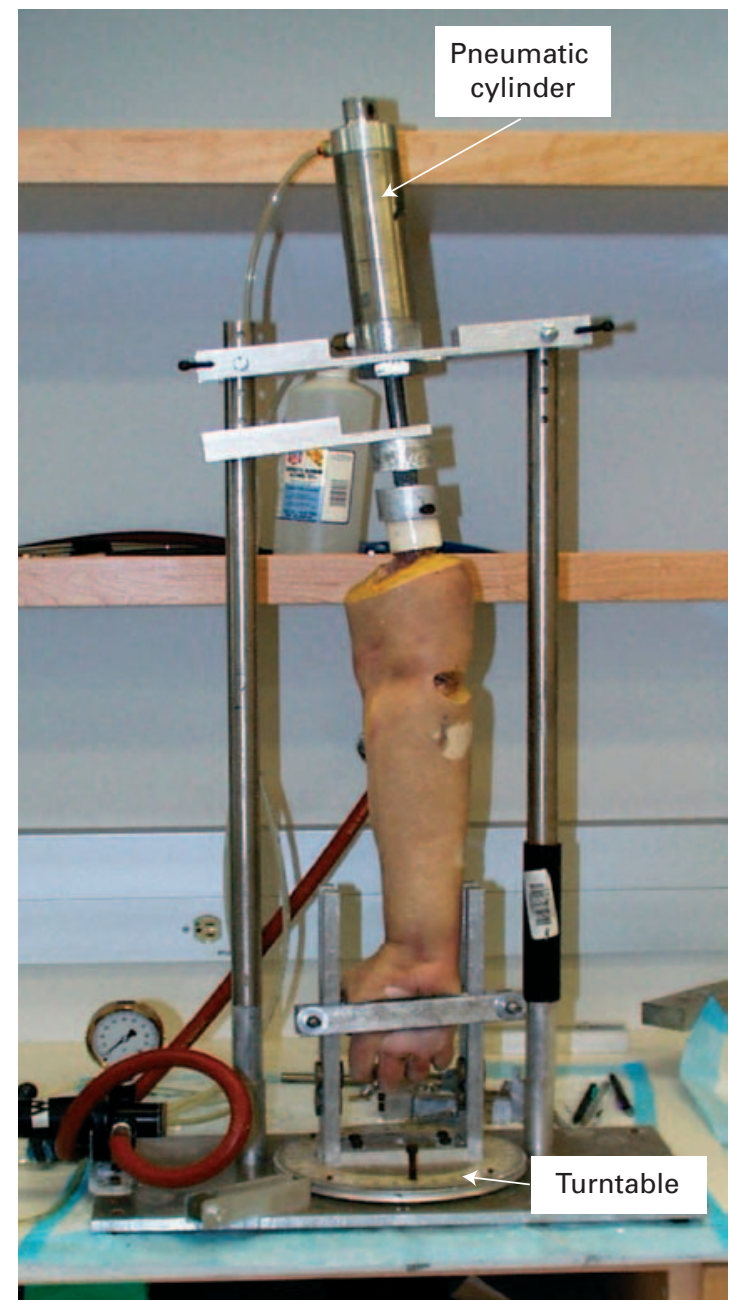

Fig. 1

Photograph of the apparatus showing the specimen with the elbow in extension, the pneumatic cylinder through which the load was applied across the elbow and the turntable which allowed the forearm to be positioned in pronation, neutral and supination.

the film in relation to the surface of the joint. After loading, the pin was removed and the arm repositioned. The pin was replaced into the second hole allowing the radius to move. Loading apparatus. The loading apparatus is shown in Figure 1 . The humerus was secured to the arm of a pneumatic piston and the hand was secured in a clamp attached to a turntable which allowed the forearm to rotate while an axial force was applied across the elbow and wrist. The elbow was positioned in full extension with the carrying angle specific to that specimen and then clamped in place. The turntable was not locked, but no rotation was noted once the position of the arm had been set. Pronation and supination were defined as $15^{\circ}$ less than the maximum that each specimen would allow by manipulation; neutral rotation was defined as the midpoint between these two positions. The elbow was loaded with increasing force which was calibrated using a load-cell. The joints of the elbow and wrist were free to move vertically under the compressive load.

Experimental procedure. A template of the radiocapitellar articulation surface was made using radiographic film. Two separate pieces of pressure-sensitive film were cut to match the template. These were sealed with clear plastic tape to form a transducer $0.3 \mathrm{~mm}$ thick which was inserted between the radial head and the capitellum. The joint was loaded for 30 seconds at $45 \mathrm{~N}$. The test was repeated at axial loads of 90 and $135 \mathrm{~N}$. These axial forces were considered to be within the physiological range. Each specimen was tested with the elbow in extension and with the forearm in the supination, neutral and pronation positions. The testing was repeated three times. The effects of loading time, ageing of the film and shear loading have been described in previous studies. ${ }^{18-21}$

After the intact specimen had been tested the radius was shortened by 2 to $3 \mathrm{~mm}$. A 3-mm segment of the mid-shaft of the radius was removed. The amount of radial shortening was calculated by adding the length of the excised bone to twice the thickness of the saw blade. The radius was shortened and fixed using a six-hole, limited contact, dynamic compression plate applied to the surface with three bicortical screws on each side of the osteotomy. Radiographs were obtained after shortening to assess the relationship of the radial head and the capitellum, as well as the radio-ulnar variance. The shortened specimen was retested.

Measurement of force, contact area and pressure. After the loading period, the pressure transducer was removed from the radiocapitellar articulation. Calibration transducers were placed into a calibrator which loaded the film with a known pressure for the same time period as the transducers used in the experiment. These allowed conversion of the colour print on the pressure film to contact pressure based upon its relative darkness. The film images and calibrations were digitised using a scanner and converted to gray-level images. A computer software programme (NIH Image $\mathrm{v}$ 6.1; National Institutes of Health, Bethesda, Maryland) was used to convert the pressure prints into pressure maps, which were used to determine the total contact area and the mean pressure. Since the relationship between the gray level and pressure was non-linear, the image was arbitrarily divided into five zones based upon the calibration pressures selected, assuming a linear relationship within each zone. From this, the area of a zone with a mean pressure could be determined. The overall mean pressure was calculated from the following equation:

$$
\mathrm{P}_{\mathrm{m}}=\sum\left(\mathrm{A}_{\mathrm{i}} \cdot \mathrm{P}_{\mathrm{i}}\right) / \mathrm{A}_{\mathrm{t}}
$$

where $\mathrm{P}_{\mathrm{m}}=$ the overall mean pressure $(\mathrm{KPa}), \mathrm{A}_{\mathrm{i}}=$ the area of zone $\mathrm{i}\left(\mathrm{mm}^{2}\right)$ (area between any two calibration values), $\mathrm{P}_{\mathrm{i}}=$ the mean pressure in zone $\mathrm{i}(\mathrm{KPa})$ and $\mathrm{A}_{\mathrm{t}}$ - the total contact area $\left(\mathrm{mm}^{2}\right)$. 
Table I. Summary of the median radiocapitellar force $(\mathrm{N})$ and contact area $\left(\mathrm{mm}^{2}\right)$, including range, for three positions of the forearm and at three axial compressive loads before and after a radial shortening osteotomy of 2 to 3 $\mathrm{mm}$. All statistical tests were based on five observations

\begin{tabular}{|c|c|c|c|c|c|c|c|c|}
\hline \multirow[b]{2}{*}{ Axial load (N) } & \multirow[b]{2}{*}{ Position } & \multicolumn{3}{|c|}{ Before osteotomy } & \multicolumn{4}{|c|}{ After osteotomy } \\
\hline & & Median & Lower & Upper & Median & Lower & Upper & p value \\
\hline \multicolumn{9}{|l|}{45} \\
\hline \multirow[t]{3}{*}{ Force } & Supination & 70.5 & 3.5 & 77.0 & 10.4 & 0.0 & 25.1 & 0.05 \\
\hline & Neutral & 96.3 & 57.6 & 136.5 & 16.5 & 7.4 & 83.7 & 0.05 \\
\hline & Pronation & 66.6 & 22.4 & 150.2 & 67.1 & 2.5 & 134.3 & 0.72 \\
\hline \multirow[t]{3}{*}{ Area } & Supination & 22.6 & 1.6 & 28.7 & 4.5 & 0.0 & 9.0 & 0.05 \\
\hline & Neutral & 37.6 & 24.5 & 41.4 & 7.4 & 3.1 & 24.6 & 0.05 \\
\hline & Pronation & 24.9 & 9.2 & 43.5 & 21.2 & 1.3 & 42.8 & 0.47 \\
\hline \multicolumn{9}{|l|}{90} \\
\hline \multirow[t]{3}{*}{ Force } & Supination & 109.5 & 25.3 & 113.8 & 15.3 & 0.0 & 60.4 & 0.05 \\
\hline & Neutral & 195.6 & 141.2 & 206.0 & 59.0 & 11.5 & 135.4 & 0.05 \\
\hline & Pronation & 163.9 & 97.1 & 232.7 & 77.5 & 14.4 & 199.9 & 0.14 \\
\hline \multirow[t]{3}{*}{ Area } & Supination & 32.0 & 10.7 & 56.6 & 6.1 & 0.0 & 17.9 & 0.05 \\
\hline & Neutral & 62.3 & 51.0 & 66.8 & 22.4 & 5.0 & 37.1 & 0.05 \\
\hline & Pronation & 51.5 & 36.9 & 66.4 & 26.9 & 6.7 & 54.1 & 0.14 \\
\hline \multicolumn{9}{|l|}{135} \\
\hline \multirow[t]{3}{*}{ Force } & Supination & 155.4 & 59.1 & 258.8 & 67.4 & 0.0 & 206.0 & 0.05 \\
\hline & Neutral & 255.8 & 233.4 & 370.4 & 89.3 & 17.2 & 166.3 & 0.05 \\
\hline & Pronation & 250.6 & 152.3 & 300.8 & 143.3 & 59.0 & 257.6 & 0.05 \\
\hline \multirow[t]{3}{*}{ Area } & Supination & 45.3 & 19.4 & 56.8 & 19.0 & 0.0 & 63.0 & 0.05 \\
\hline & Neutral & 75.2 & 63.7 & 123.2 & 29.5 & 7.8 & 44.6 & 0.05 \\
\hline & Pronation & 75.3 & 45.8 & 86.9 & 49.0 & 25.4 & 66.6 & 0.05 \\
\hline
\end{tabular}

This method approximates the non-linear behaviour of the film by dividing the data into discrete linear zones. Previous studies have shown that it produces an estimate of total force (mean pressure multiplied by contact area) which agrees with a known force applied over a test area. ${ }^{20}$ The mean radiocapitellar force was determined by dividing the overall mean pressure $\left(\mathrm{P}_{\mathrm{m}}\right)$ by the total contact area $\left(\mathrm{A}_{\mathrm{t}}\right)$.

Analysis of data. One specimen was used to set up the loading apparatus and to determine the experimental protocols. Data from five upper limbs were, therefore, used for analysis. A mean value was calculated from the three measurements for each specimen at each load and each position of the hand. This was used as an independent data sample. Median contact areas and forces were determined in supinated, neutral, and pronated positions of the forearm and at $45 \mathrm{~N}, 90 \mathrm{~N}$ and $135 \mathrm{~N}$ of axial load through the joint, as described above. A Wilcoxon signed rank test, using nonparametric statistics for small samples, was employed to compare measurements between the intact and osteotomised specimens. The null hypothesis was that radial shortening of 2 to $3 \mathrm{~mm}$ would have no effect on the radiocapitellar contact area and force. A statistically significant difference between the intact and osteotomised areas and forces was set at $\mathrm{p}<0.05$.

\section{Results}

Table I gives a summary of the mean radiocapitellar force and contact area in the three positions of the forearm (supination, neutral and pronation) and at three axial loads (45 $\mathrm{N}, 90 \mathrm{~N}$ and $135 \mathrm{~N}$ ) before and after radial shortening osteotomy of 2 to $3 \mathrm{~mm}$. Figure 2 shows representative prints from one specimen in supination.

The mean radiocapitellar force decreased significantly after radial shortening in all cases except pronation at $45 \mathrm{~N}$ and $90 \mathrm{~N}$ of axial load. The mean decrease in force over all positions and axial loads with significant changes was approximately $70 \%$. The mean radiocapitellar contact area decreased similarly for all positions except pronation at $45 \mathrm{~N}$ and $90 \mathrm{~N}$, again with an overall mean decrease of approximately $66 \%$.

\section{Discussion}

Traditional surgical treatments of osteochondritis dissecans of the capitellum have been unreliable, Recently, radiocapitellar unloading by shortening of the lateral column of the distal humerus has shown promise. ${ }^{6}$ In seven patients who underwent closing-wedge osteotomy of the capitellum for osteochondritis dissecans, the radiological distance between the radius and the capitellum was increased and clinical symptoms were relieved. The biomechanical effect of capitellar shortening has not been studied experimentally. The procedure is less familiar and carries a higher risk than radial shortening. Our results indicate that radial shortening significantly reduces the mean force and contact area across the radiocapitellar articulation and therefore it may be a viable alternative to capitellar shortening.

When the radius is shortened at its mid-shaft by $3 \mathrm{~mm}$ and fixed in this position, three situations are possible. First, the distal fragment may be drawn proximally by $3 \mathrm{~mm}$, resulting in radial shortening at the wrist. Secondly, the proximal fragment may be drawn distally from the 


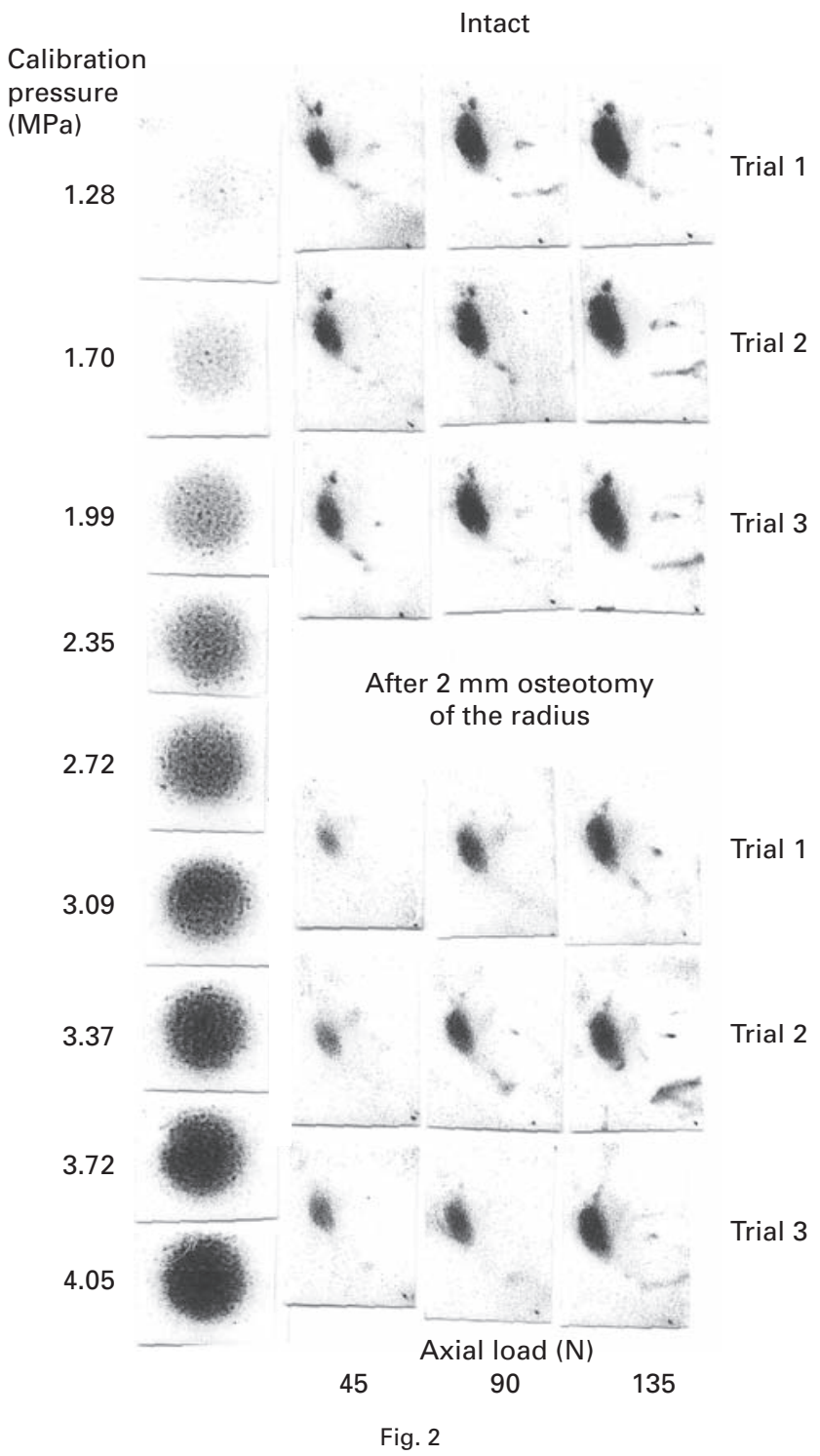

Sets of prints from a specimen tested in supination. The reference calibration pressures of film are shown in the left column. Results are shown for the intact radius and after osteotomy.

capitellum creating radial shortening at the elbow and thirdly, the effect may be a combination of the above. Radial shortening has been shown to reduce the force transmitted to the lunate bone in Kienböck's disease. ${ }^{22}$ This implies that the distal radius moves away from the wrist. By demonstrating a lower radiocapitellar force with radial shortening our results imply that, when the radius is shortened, the radial head moves distally. Radiological analysis of our specimens indicated that the radial head moved away from the capitellum and the distal radius moved away from the wrist.

Shepard, Markolf and Dunbar ${ }^{23}$ addressed the biomechanical effects of distal radial shortening on the load transmission between the radius and ulna. They estimated that the load on the distal ulna increased by approximately $10 \%$ for each millimetre of radial shortening. We found a mean reduction in force of approximately $55 \%$ in the radiocapitellar joint for $3 \mathrm{~mm}$ of radial shortening. Both Shepard et $\mathrm{al}^{23}$ and Ofuchi et $\mathrm{al}^{24}$ have pointed out the important contribution of the interosseous membrane in load-sharing between the radius and ulna, especially when the forearm was supinated more than $35^{\circ}$. It is interesting to note that our study showed that the greatest reduction in force occurred in supination and the smallest in pronation.

Our study has some limitations. First, we tested cadaver specimens which were fresh-frozen upper limbs with preservation of bone and soft tissues. Secondly, a lateral capsulotomy of the elbow was performed for the insertion of the pressure film between the radius and capitellum. The collateral ligaments and osseous architecture responsible for the stability of the elbow were not disturbed. Thirdly, only five specimens were analysed, excluding the first limb which was used to determine the details of the protocol. Each specimen served as its own control, reducing variation in the data. Even with this small number, statistically significant differences in the contact characteristics of the joint between the intact and osteotomised limbs were apparent. Fourthly, mid-shaft radial osteotomy results in proximal movement of the distal end of the bone away from the wrist in addition to distal movement of the radial head away from the capitellum. This implies that the procedure would be contraindicated in the setting of positive ulnar variance and lastly, the model represents only a single loading situation, direct axial loading. No muscle forces were modelled. However, the major load causing pressure across the joint is axial compression, from external sources such as bodyweight, and internal sources such as muscle tension.

Our study has shown the effectiveness of radial shortening in reducing the compressive forces across the radiocapitellar articulation through a combination of the decreased contact area of the radial head and the transfer of load to the humero-ulnar joint. The effects on the stability of the elbow are unknown. Unloading of the radiocapitellar articulation may alleviate symptoms and alter the natural history of osteochondritis dissecans of the capitellum. Clinical investigation is necessary to determine the efficacy of the procedure in the treatment of this disorder.

No benefits in any form have been received or will be received from a commercial party related directly or indirectly to the subject of this article.

\section{References}

1. Jawish R, Rigault P, Padovani JP, et al. Osteochondritis dissecans of the humeral capitellum in children. Eur J Pediatr Surg 1993;3:97-100.

2. Singer KM, Roy SP. Osteochondritis of the humeral capitellum. Am J Sports Med 1984; 12:351-60.

3. Byrd JW, Jones KS. Arthroscopic surgery for isolated capitellar osteochondritis dissecans in adolescent baseball players: minimum three-year follow-up. Am J Sports Med 2002;30:474-8.

4. Hresko MT, Rosenberg BN, Pappas AM. Excision of the radial head in patients younger than 18 years. J Pediatr Orthop 1999;19:106-13.

5. Janarv PM, Hesser U, Hirsch G. Osteochondral lesions in the radiocapitellar joint in the skeletally immature: radiographic, MRI, and arthroscopic findings in 13 consecutive cases. J Pediatr Orthop 1997;17:311-14. 
6. Kiyoshige Y, Takagi M, Yuasa K, Hamasaki M. Closed-wedge osteotomy for osteochondritis dissecans of the capitellum: a 7- to 12-year follow-up. Am J Sports Med 2000;28:534-7

7. Takahara M, Ogino T, Takagi M, et al. Natural progression of osteochondritis dissecans of the humeral capitellum: initial observations. Radiology 2000;216:207-12.

8. Takahara M, Ogino T, Fukushima S, Tsuchida H, Kaneda K. Nonoperative treatment of osteochondritis dissecans of the humeral capitellum. Am J Sports Med 1999 27:728-32.

9. Baumgarten TE, Andrews JR, Satterwhite YE. The arthroscopic classification and treatment of osteochondritis dissecans of the capitellum. Am J Sports Med 1998; 26:520-3.

10. Byrd JW, Elrod BF, Jones KS. Elbow arthroscopy for neglected osteochondritis dissecans of the capitellum. J South Orthop Assoc 2001;10:12-16.

11. Krijnen MR, Lim L, Willems WJ. Arthroscopic treatment of osteochondritis dissecans of the capitellum: report of 5 female athletes. Arthroscopy 2003;19:210-14.

12. Peterson RK, Savoie FH 3rd, Field LD. Osteochondritis dissecans of the elbow. Instr Course Lect 1999;48:393-8.

13. Woodward AH, Bianco AJ Jr. Osteochondritis dissecans of the elbow. Clin Orthop 1975; $110: 35-41$

14. Takahara M, Ogino T, Sasaki I, et al. Long term outcome of osteochondritis dissecans of the humeral capitellum. Clin Orthop 1999;363:108-15

15. Ruch DS, Cory JW, Poehling GG. The arthroscopic management of osteochondritis dissecans of the adolescent elbow. Arthroscopy 1998;14:797-803.
16. Oka Y, Ohta K, Fukuda H. Bone-peg grafting for osteochondritis dissecans of the elbow. Int Orthop 1999;23:53-7.

17. Garrett JC. Fresh osteochondral allografts for treatment of articular defect in osteochondritis dissecans of the lateral femoral condyle in adults. Clin Orthop 1994:303: 33-7.

18. Viola RW, Kiser PK, Bach AW, Hanel DP, Tencer AF. Biomechanical analysis of capitate shortening with capitate-hamate fusion in the treatment of Kienböck disease. J Hand Surg [Am] 1998;23:395-401.

19. Augsberger S, Necking L, Horton J, Bach AW, Tencer AF. A comparison of scaphoid-trapezium-trapezoid fusion and four-bone tendon weave for scapholunate dissociation. J Hand Surg [Am] 1992;17:360-9.

20. Sangeorzan BJ, Ananthakrishnan D, Tencer AF. Contact characteristics of the subtalar joint following a simulated calcaneum fracture. J Orthop Trauma 1995;9:251-8.

21. Wagner WF Jr, Tencer AF, Kiser P, Trumble TE. Effects of intra-articular distal radius depression on wrist joint contact characteristics. J Hand Surg [Am] 1996;21: $554-60$.

22. Quenzer DE, Dobyns JH, Linscheid RL, Trail IA, Vidal MA. Radial recession osteotomy for Kienböck's disease. J Hand Surg [Am] 1997;22:386-95.

23. Shepard MF, Markolf KL, Dunbar AM. Effects of radial head excision and dista radial shortening in cadaver forearms. J Bone Joint Surg [Am] 2001;83-A: 92-100.

24. Ofuchi S, Takahashi K, Yamagata M, et al. Pressure distribution in the humeroradial joint and force transmission to the capitellum during rotation of the forearm: effects of the Sauve-Kapandji procedure and incision of the interosseous membrane. J Orthop Sci 2001:6:33-8. 